\title{
Functionalization of gold surfaces with copoly(DMA-NAS-MAPS) by dip coating: Surface characterization and hybridization tests
}

 \\ R. Bertacco ${ }^{\text {a }}$, M. Chiari ${ }^{b}$ \\ a LNESS-Dipartimento di Fisica del Politecnico di Milano, Via Anzani 42, 22100 Como, Italy \\ b Istituto di Chimica del Riconoscimento Molecolare, CNR, Via Mario Bianco 9, 20131 Milan, Italy \\ ${ }^{\mathrm{c}}$ Department of Molecular and Translational Medicine, University of Brescia, Viale Europa 11, 25123 Brescia, Italy
}

\section{A R T I C L E I N F O}

\section{Article history:}

Received 5 June 2013

Received in revised form 9 August 2013

Accepted 25 August 2013

Available online 4 September 2013

\section{Keywords:}

Gold functionalization

Copoly(DMA-NAS-MAPS)

Chemiluminescence

Surface plasmon resonance

Atomic force microscopy

$\mathrm{X}$-ray photoemission spectroscopy

\begin{abstract}
A B S T R A C T
In this work, a new method to functionalize a gold surface by dip coating with a functional copolymer is presented. The coating procedure is simple, robust and can be accomplished in less than one hour. Atomic force microscopy (AFM) scratch tests reveal the presence of a homogeneous polymer coating with a thickness of $2.5 \mathrm{~nm}$. X-ray photoemission spectroscopy spectra from C1s, N1s and O1s levels present the typical fingerprints of the polymeric overlayer, i.e. the characteristic peaks from $\mathrm{CNC}=\mathrm{O}$ and $\mathrm{NC}=\mathrm{O}$ groups.

Surface plasmon resonance (SPR) binding assays were used to check the coating functional properties. Immobilization of heparin to SPR gold surfaces functionalized with copoly(DMA-NAS-MAPS)- followed by binding analysis with the well known heparin binding protein fibroblast growth factor 2 yield binding kinetic parameters comparable to those obtained with commercially available carboxymethyl dextranfunctionalized sensorchips, thus confirming the great potential of the proposed technique.
\end{abstract}

(c) 2013 Elsevier B.V. All rights reserved.

\section{Introduction}

In the last ten years, we assisted to a great development of microarray analysis techniques for proteomics and genomics [1]. In this scenario a key-point is the chemical functionalization of different substrates (glass, silicon, gold) [2] for an effective and selective immobilization of bio-macromolecules such as DNA, oligonucleotides and proteins.

In particular, there is a strong interest in developing methods for gold surface functionalization, as this metal is widely used in biosensing. In surface plasmon resonance (SPR), a thin layer of gold on a high refractive index glass surface absorbs laser light, producing electron waves (surface plasmons) on the gold surface. This occurs only at a specific angle and wavelength of incident light which are highly dependent on the surface properties. For this reason, the binding of a target ligand to a receptor immobilized on the gold surface produces a measurable signal related to the concentration of the target [3].

In electrochemical biosensors, an enzymatically catalyzed reaction, involving the target analyte, produces or absorbs electrons on the active electrode surface causing either electron transfer across

\footnotetext{
* Corresponding author. Tel.: +39 0313327307; fax: +39 0313327617

E-mail address: daniela.petti@polimi.it (D. Petti).
}

the double layer (thus producing a current) or contributing to the double layer potential (finally leading to a voltage) [4].

Several functionalization strategies for gold have been described $[2,5]$ and reference therein] including surface modification with silanes [6] and functional polymers. In SPR the unquestioned coating choice is based on dextran. A stable dextran layer is obtained by covalent binding of the polymer to a functional sublayer formed on the surface by self-assembling of a thiol bearing molecule. The characteristics of the dextran coated surface have been optimized and the quality of this coating has greatly contributed to the success of SPR technology. However, the procedure for binding dextran is cumbersome and requires multistep chemical reactions which may be difficult to control.

In the case of the dextran coating as in other bioassays involving gold [7], the coating formation requires spontaneous assembly of chemically reactive alkene thiols leading to formation of so called self-assembled monolayers (SAM) [8-10]. By placing a gold substrate into a millimolar solution of an alkanethiol in ethanol a variety of chemically reactive groups can be introduced by a reaction between gold and thiols. This reaction is well-known and widely adopted due to the fact that it is straightforward and requires commercially available chemical reagents. In addition the binding between gold and thiol is very stable owing to its covalent character $[11,12]$. However, the formation of a well-assembled monolayer strongly depends on the purity of the alkanethiol being 
used. The presence of even low levels of contaminants can result in a disordered, non-ideal monolayer. Unfortunately, typical impurities in thiol compounds are thiolated precursor molecules, not properly separated during the purification process [13].

In this work we present an alternative approach to surface modification that is fast, robust and easy to perform even in laboratories that do not have a strong surface chemistry background. In particular, we propose a method based on a polymeric thin coating made of N,N-dimethylacrylamide (DMA) bearing silanating (MAPS) and chemically reactive (NAS) moieties: poly(DMA-NAS-MAPS). The copoly(DMA-NAS-MAPS) was developed for DNA and protein microarray assays on microscope glass slide [14] and on silicon [15]. As shown in previous papers [6], the deposition by "dip and rinse" coating of a thin layer of this polymer represents a fast, inexpensive and robust method to covalently bind proteins and amino-modified DNA probes. In addition, the film is stable in aqueous buffers containing various additives, even at water boiling temperature and, due to its hydrophilic nature and high homogeneity, it minimizes non-specific biomolecular interactions. The last feature is highly desirable for surface recognition bioassays, for which specificity is difficult to achieve. Furthermore, the proposed method, employing non surface-specific material modifications, can be easily used also to form uniform coatings on many different materials other then gold, such as glass, silicon dioxide, silicon nitride and titanium dioxide [15], thus being applied to different biosensing problems and techniques. This versatility can be particularly important in application employing sensors that consist of more than one material. The use of copoly(DMA-NAS-MAPS) allows the derivatization of all the different regions of the device in single step.

The morphological and chemical properties of this polymeric coating on gold surfaces have been studied by means of atomic force microscopy (AFM) and X-ray photoemission spectroscopy (XPS). These techniques reveal that the polymer is immobilized on the surface with the proper chemical composition and expected thickness. Furthermore we found a limited impact on the gold underlayer, thus allowing the use of the proposed functionalization method for techniques such as SPR. To demonstrate the compatibility of this derivatization process with standard bioassays, two different experiments have been carried out: a DNA hybridization experiment with chemiluminescence and surface plasmon resonance (SPR) to assay the binding of fibroblast growth factor (FGF2) in solution to immobilized heparin. Independently from the transducer employed, results comparable to those obtained with commercially available carboxymethyl dextran-functionalized sensorchips were obtained. This indicates the potential of the coating technique to implement robust protocols of biomolecules immobilization onto gold coated surfaces for biosensing applications.

\section{Materials and methods}

\subsection{Chemicals}

Tris(hydroxymethyl)aminomethane (TRIS), ethanolamine, saline-sodium citrate (SSC), ammonium sulfate, sodium dodecyl sulfate (SDS), phosphate buffer solution (PBS), $N, N$ dimethylacrylamide (DMA) and [3-(methacryloyl-oxy)propyl] trimethoxysilane (MAPS) were purchased from Sigma (St. Louis, MO). N,Nacryloyloxysuccinimide (NAS) was from Polysciences (Warrington, PA). Oligonucleotides were synthesized by MWGBiotech AG (Ebevsberg, Germany). Streptavidin labeled by HRP (Horse Radish Peroxidase) from Jackson Immunoresearch. Heparin $(13.6 \mathrm{kDa})$ was obtained from Laboratori Derivati Organici Spa (Milan, Italy). SuperSignal ELISA Femto maximum Sensitivity kit from ThermoScientific. Human recombinant fibroblast growth factor 2 (FGF2) was expressed in Escherichia coli and purified as described in [16].

\subsection{Gold surface preparation and derivatization}

For initial tests, gold films on Si were prepared in-house. Silicon wafers were coated with $3 \mathrm{~nm} \mathrm{Cr}$ (to promote gold adhesion) and $50 \mathrm{~nm}$ Au, by means of electron beam evaporation. Copoly(DMANAS-MAPS), whose chemical structure is shown in Fig. 1, was synthesized and characterized as described in a previous work $[17,14]$. The gold surface was treated for ten minutes in an Oxygen Plasma Generator (Harrick Plasma Cleaner) and then immersed for $30 \mathrm{~min}$ in a copoly(DMA-NAS-MAPS) solution ( $1 \% \mathrm{w} / \mathrm{v}$ in a water solution of ammonium sulfate at a $20 \%$ saturation level). The silicon slides were then extensively washed with water and dried under vacuum at $80^{\circ} \mathrm{C}$ for $15 \mathrm{~min}$.

\subsection{AFM measurements}

AFM measurements were performed with a VEECO Innova AFM. The morphological characterization was carried out in tapping mode with 512 samples/line, frequency of $0.8 \mathrm{~Hz}$ and $4-10 \mu \mathrm{m}$ scan range. The thickness of the polymeric layer was evaluated by AFM-tip scratch test [18]. This technique consists in scratching the coating with the AFM tip while the normal force applied is set to a value high enough to penetrate the layer but low enough to avoid significant tip or substrate damaging. The scratch was made in contact mode onward and in lift mode backward (start height $0.3 \mu \mathrm{m}$, lift height $0.3 \mu \mathrm{m}$ ) with 30 continuous scan cycles, 256 samples/line, $62.75 \mathrm{~Hz}, 1 \mu \mathrm{m}$ scan range. After scratching, the area was imaged in tapping mode with the same tip used for scratching. In this way the area of interest is easily identified within the active scan area of the AFM.

\subsection{XPS experiments}

XPS experiments were performed in a multichamber ultrahighvacuum (UHV) system described in detail elsewhere [19]. Photoelectrons were excited by $\mathrm{Al} \mathrm{K} \alpha(h \nu=1486.67 \mathrm{eV})$ or $\mathrm{Mg} \mathrm{K} \alpha$ $(h \nu=1253.6 \mathrm{eV})$ radiation, and analyzed by a $150 \mathrm{~mm}$ hemispherical analyzer (SPECS Phoibos 150). The angular acceptance set for this work was about $\pm 6^{\circ}$, and the spatial resolution was $1.4 \mathrm{~mm}$. Two modes of operation have been employed: (M1) pass energy of $50 \mathrm{eV}$ and $\mathrm{Al} \mathrm{K \alpha}$ line (total energy resolution of $1.643 \mathrm{eV}$ ) to evaluate the stoichiometry of the polymer; (M2) pass energy of $10 \mathrm{eV}$ and $\mathrm{Mg} \mathrm{K} \alpha$ line (total energy resolution of $0.841 \mathrm{eV}$ ) in order to study the lineshape of the characteristic peaks. The energy scale of the spectra has been calibrated by measuring a Ta foil in good electrical contact with the sample.

\subsection{Chemiluminescence test}

A 23-mer, 5'-amine-modified oligonucleotide synthesized by MWG-Biotech AG (Ebevsberg, Germany), $100 \mu \mathrm{M}$ stock solution, 5'-NH2-(CH2)6-GCC CAC CTA TAA GGT AAA AGT GA, was dissolved in $150 \mathrm{mM}$ sodium phosphate buffer at $\mathrm{pH}$ 8.5. A $10 \mu \mathrm{M}$ solution of this oligonucleotide was printed on coated slides to form a $15 \times 15$ array using a piezoelectric spotter (SciFLEXARRAYER S5; Scienion). Spotting was done at $20^{\circ} \mathrm{C}$ in an atmosphere of $50 \%$ humidity. The oligonucleotides were coupled to the surfaces by overnight incubation in an uncovered storage box, laid in a sealed chamber, saturated with sodium chloride $\left(40 \mathrm{~g} / 100 \mathrm{~mL} \mathrm{H}_{2} \mathrm{O}\right)$, at room temperature. After incubation, all residual reactive groups of the coating polymer were blocked by dipping the printed slides in $50 \mathrm{mM}$ ethanolamine/0.1 M Tris $\mathrm{pH} 9.0$ at $50^{\circ} \mathrm{C}$ for $15 \mathrm{~min}$. After discarding the blocking solution, the slides were rinsed two times with water and shaken for $15 \mathrm{~min}$ in $4 \times$ SSC/0.1\% SDS buffer, pre-warmed at $50^{\circ} \mathrm{C}$, and briefly rinsed with water. An oligonucleotide, complementary to the one spotted on the surface, at a 


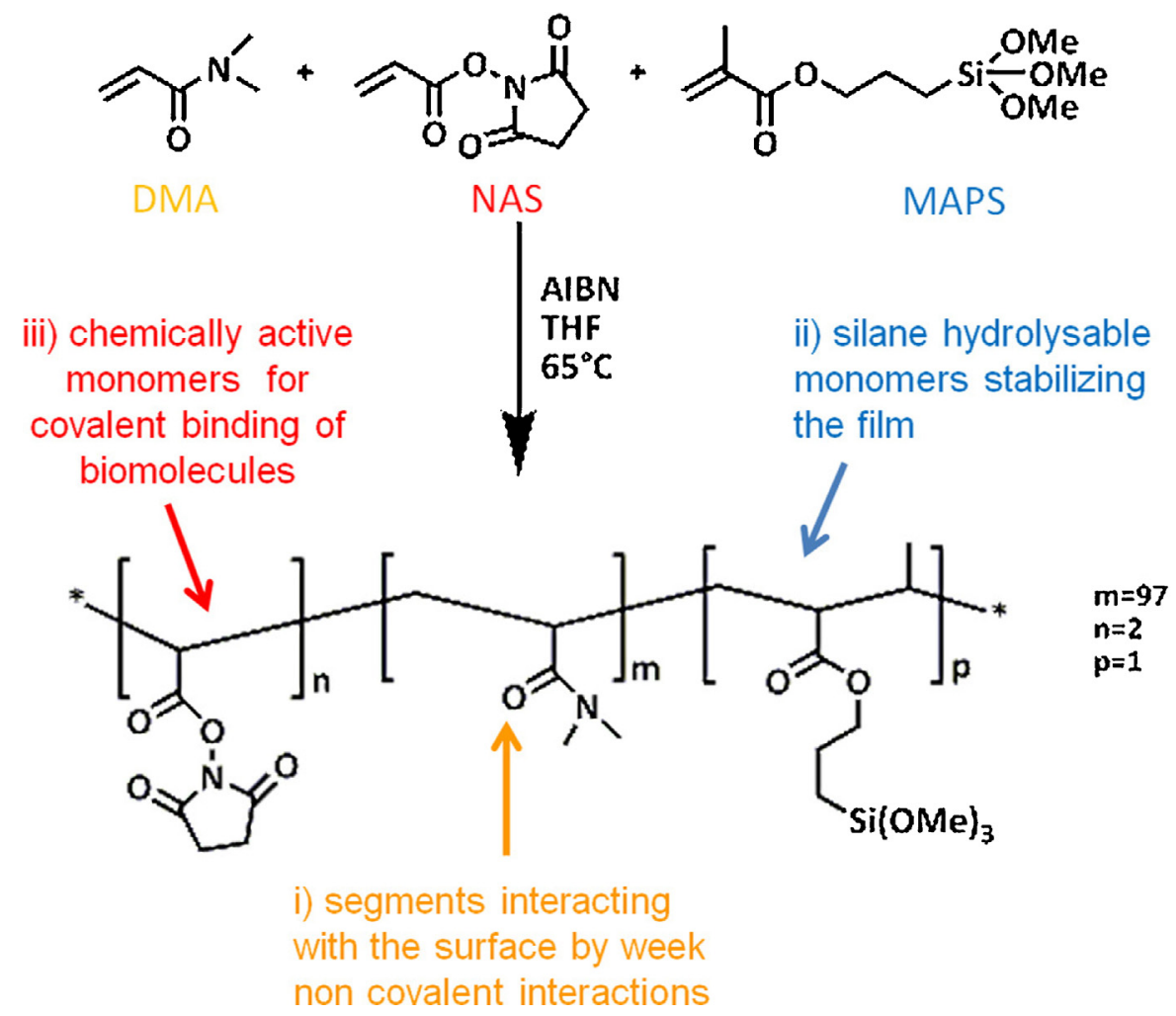

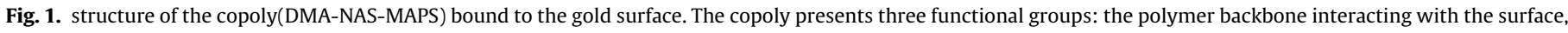
the pending silane hydrolysable monomers that stabilizing the film and the chemically active monomers allowing the covalent binding of biomolecules.

$1.0 \mu \mathrm{M}$ concentration $\left(2.5 \mu \mathrm{L} / \mathrm{cm}^{2}\right.$ of coverslip) was dissolved in the hybridization buffer $(2 \times$ SSC, $0.1 \%$ SDS and $0.2 \mathrm{mg} / \mathrm{mL} \mathrm{BSA})$ and immediately applied to microarrays. The complementary oligonucleotide has the sequence $5^{\prime}$-TCA CTT TTA CCT TAT AGG TGG GC-3' and is labeled with biotin in $5^{\prime}$ position. The surfaces, placed in a hybridization chamber, were transferred to a humidified incubator at a temperature of $65^{\circ} \mathrm{C}$ for $2 \mathrm{~h}$. After hybridization, the slides were first washed with $4 \times$ SSC at room temperature to remove the coverslip and then with $2 \times$ SSC/0.1\% SDS at hybridization temperature for $5 \mathrm{~min}$. This operation was repeated two times and was followed by two washing steps with $0.2 \times$ SSC and $0.1 \times$ SSC for $1 \mathrm{~min}$ at room temperature. Streptavidin labeled by HRP (Horse Radish Peroxidase) from Jackson Immunoresearch at the concentration of $1 \mu \mathrm{g} / \mathrm{mL}$ in PBS buffer was applied to the gold surface for $60 \mathrm{~min}$. After a short rinse in PBS and water, the slides were dried and chemiluminescence was developed using the SuperSignal ELISA Femto Maximum Sensitivity kit from ThermoScientific according to the manufacturer instructions. The chemiluminescence signal was registered at $0.2 \mathrm{~s}$ exposure time using a homemade set up equipped with a Q Imaging CCD Camera.

\subsection{Surface plasmon resonance (SPR)}

For SPR experiment, a naked gold sensorchip (Xantech Bioanalytics, Dusseldorf, Germany) was functionalized with copoly(DMA-NAS-MAPS) as follows: the gold chip was treated with oxygen plasma in a Plasma Cleaner, Harrick Plasma (Ithaca, NY, USA) to clean the surface. Immediately after the oxygen plasma treatment, the sensorchip was dipped in an aqueous solution of poly(DMA-NAS-MAPS) in ammonium sulphate at $20 \%$ of saturation level for $30 \mathrm{~min}$, and then it was rinsed with DI water, dried with nitrogen flow and cured under vacuum at $80^{\circ} \mathrm{C}$ for $15 \mathrm{~min}$. The polymer was functionalized with streptavidin by spotting $1 \mathrm{mg} / \mathrm{mL}$ solution of protein dissolved in PBS using a piezoelectric spotter
(SciFLEXARRAYER S5; Scienion). The merged spots, printed at $20{ }^{\circ} \mathrm{C}$ in an atmosphere of $50 \%$ humidity, created a continuous protein film. To promote the protein attachment, the chip was incubated overnight in an uncovered storage box, laid in a sealed chamber, saturated with sodium chloride $\left(40 \mathrm{~g} / 100 \mathrm{~mL} \mathrm{H}_{2} \mathrm{O}\right)$, at room temperature. The functionalized sensorchip was positioned in a BIAcore X instrument (GE-Healthcare, Milwaukee, WI) and the surface was conditioned with 3 consecutive 1-min injections of $1 \mathrm{M}$ $\mathrm{NaCl}$ in $50 \mathrm{mM} \mathrm{NaOH}$ before heparin immobilization. Biotinylated heparin $[100 \mathrm{ng} / \mathrm{mL}$ in $10 \mathrm{mM}$ HEPES buffer $\mathrm{pH} 7.4$ containing $150 \mathrm{mM} \mathrm{NaCl}, 3 \mathrm{mM}$ EDTA, 0.005\% surfactant P20 (HBS-EP)] was injected onto the copoly(DMA-NAS-MAPS) functionalized sensorchip for $4 \mathrm{~min}$ at a flow rate of $5 \mu \mathrm{L} / \mathrm{min}$. Increasing concentrations of FGF2 in HBS-EP were injected over the heparin for $4 \mathrm{~min}$ at a flow rate of $30 \mu \mathrm{l} / \mathrm{min}$ (to allow their association with immobilized heparin) and then washed until dissociation was observed. A sensorchip coated with streptavidin was used to evaluate the non-specific binding and for blank subtraction. After every run, the sensorchip was regenerated by injection of $2 \mathrm{M} \mathrm{NaCl}$. Kinetic parameters were calculated by using the non linear fitting software package BIAevaluation using a single site model.

\section{Results and discussion}

\subsection{Polymeric coating characterization}

A copolymer of dimethylacrylamide, N-hydroxysuccinimide and [3-(methacryloyl-oxy)propyl]trimethoxysilane has been used to form, by dip and rinse coating, a thin film on the gold surface. The copolymer structure is shown in Fig. 1, where relative molecular weights and molecular weight distributions of the copolymer were determined by gel permeation chromatography (GPC) in previous works [20]. It has three functional portions: (i) segments that might interact with the surface by week, non covalent bonds, van 
(a)

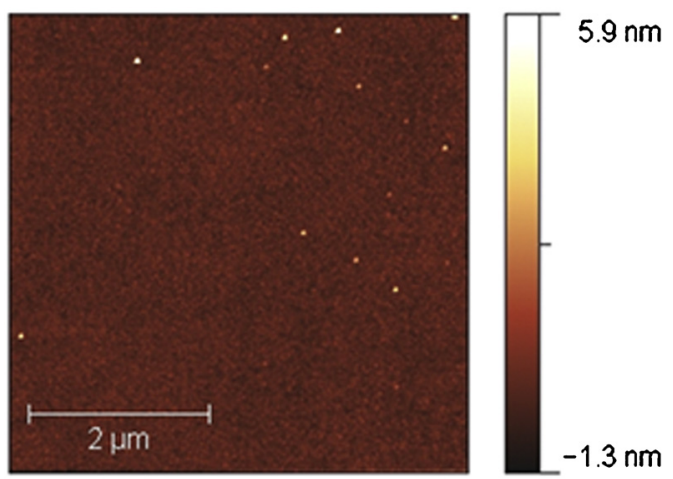

(b)

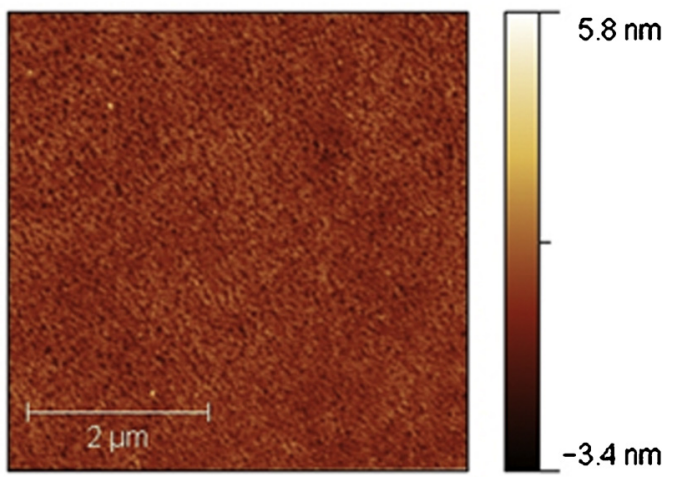

Fig. 2. AFM image on a $5 \mu \mathrm{m} \times 5 \mu \mathrm{m}$ area of the free gold (panel a) and polymer coated (panel b) surface. The roughness RMS is 0.4 and $0.6 \mathrm{~nm}$.

der Waals or hydrophobic forces (polymer backbone-DMA) favored by gold hydrophobicity, (ii) pending silane hydrolysable monomers that stabilizes the film by promoting condensation between different chains (MAPS), and (iii) chemically active monomers that react with amines present in the protein later chains allowing the covalent binding of biomolecules to the gold surface (NAS). This polymer forms a film on a number of materials of different chemical composition such as glass [14], silicon oxide [15] and organic polymers $[21,22]$. However, the specific mechanism by which the polymer forms a thin layer on the gold surface is not fully understood.

The AFM images taken from the gold and polymer modified surface are presented in Fig. 2 (panels a and b, respectively), for the case of $\mathrm{Au} / \mathrm{Cr} / \mathrm{Si}$ samples. The root mean square (RMS) roughness of the gold surface is about $0.36 \mathrm{~nm}$ on an area of $5 \mu \mathrm{m} \times 5 \mu \mathrm{m}$, while the polymer coated surface presents a RMS roughness of $0.60 \mathrm{~nm}$. The minor roughness increase suggests a uniform and continuous polymeric coating mimicking the gold morphology. In Fig. 3a a representative nano-scratch image of the layer and in Fig. $3 \mathrm{~b}$ some depth profiles (taken along the white lines) are shown. In the scratched area $(1 \mu \mathrm{m} \times 1 \mu \mathrm{m})$ a roughness of $0.48 \mathrm{~nm}$ RMS is recovered. The comparison of the AFM phase contrast (data not shown) on the scratched area and on the overlayer, reveals that the two zones are made of different materials. This proves that the scratch has fully removed the polymeric coating. From depth profiles of Fig. $3 \mathrm{~b}$, we can then evaluate a layer thickness $d=2.5 \pm 0.3 \mathrm{~nm}$, consistent with the thickness evaluated by scratch tests performed on a $\mathrm{SiO}_{2}$ surface coated with the same polymer [15]. An important characteristic of this polymeric coating is its ability to swell in aqueous solutions. The swelling, also present in other polymers, depends on the properties of the polymer of interest such as its molecular weight, as well as the environmental conditions such as temperature, or $\mathrm{pH}[20]$. (a)

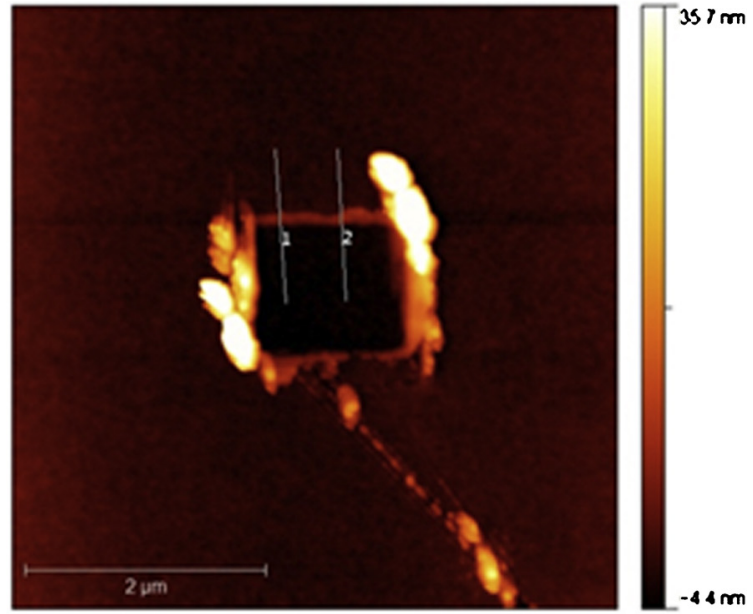

(b)

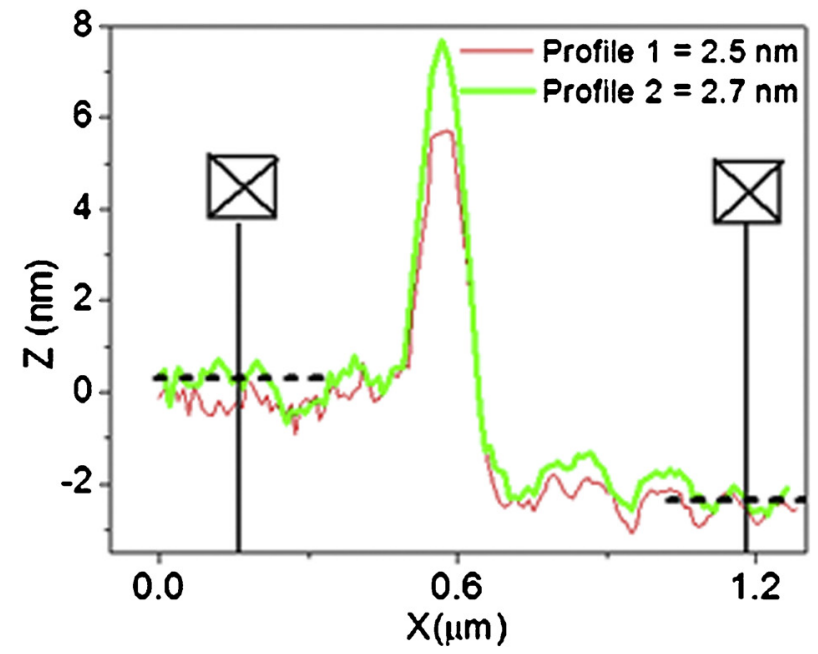

Fig. 3. Panel a: $4.5 \mu \mathrm{m} \times 4.5 \mu \mathrm{m}$ AFM image of the sample after scratch; the scratched area is $1 \mu \mathrm{m}^{2}$. Panel b: depth profiles from the lines of panel a. The estimated polymer thickness is $2.5 \pm 0.3 \mathrm{~nm}$, respectively.

The chemical characterization of the polymeric coating has been carried out by XPS. Wide scans taken on coated samples show the characteristic peaks of four chemical elements: gold from the substrate and carbon, oxygen, nitrogen coming from the polymer. In Table 1 , the intensity ratios $01 \mathrm{~s} / \mathrm{C} 1 \mathrm{~s}$, and $\mathrm{N} 1 \mathrm{~s} / \mathrm{C} 1 \mathrm{~s}$ are shown, after normalization to the cross section, analyzer transmission and probing depth. To this scope, we normalized the peak intensity to the function $f(\lambda)=\lambda^{*}(1-\exp (-d / \lambda))$, where $\lambda$ is the electron escape depth [23]. The surface was analyzed at two collection angles from the sample normal: $0^{\circ}$ and $60^{\circ}$, the last one providing higher surface sensitivity due to the finite escape depth of the emitted photoelectrons.

Table 1

Relative intensities of $\mathrm{N} 1 \mathrm{~s}, \mathrm{O} 1 \mathrm{~s}$ and $\mathrm{C} 1 \mathrm{~s}$ peaks taken at $0^{\circ}, 60^{\circ}$ collection angle and relative nominal atomic ratios (from the polymer composition).

\begin{tabular}{lcll}
\hline & $\begin{array}{c}\text { Collection } \\
\text { angle }\left(^{\circ}\right)\end{array}$ & $\begin{array}{l}\text { N1s/C1s } \\
\text { intensity ratio }\end{array}$ & $\begin{array}{l}\text { O 1s/C1s } \\
\text { intensity ratio }\end{array}$ \\
\hline XPS & 0 & $0.17 \pm 0.02$ & $0.16 \pm 0.02$ \\
& 60 & $0.14 \pm 0.02$ & $0.15 \pm 0.02$ \\
copoly(DMA-NAS-MAPS) & - & 0.19 & 0.20 \\
$\quad$ composition & & & \\
\hline
\end{tabular}




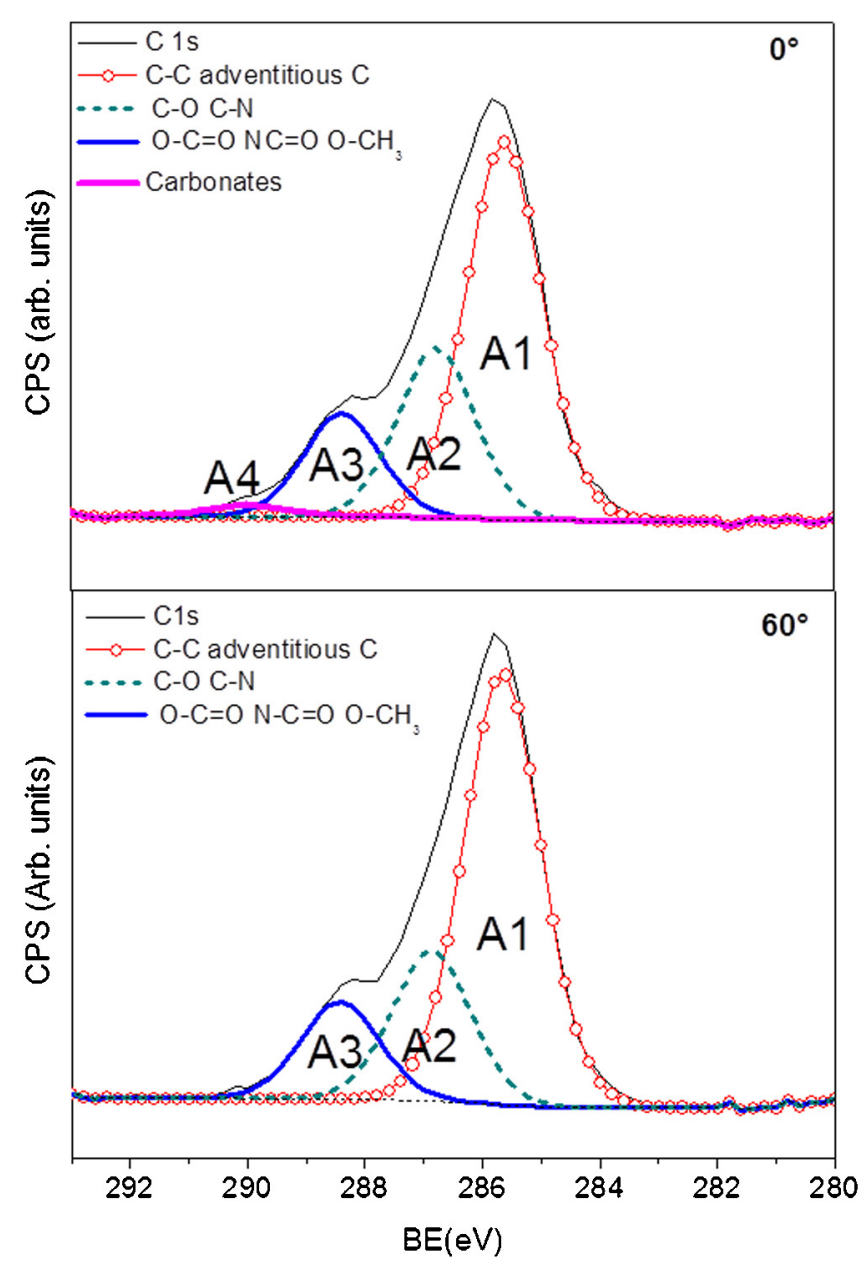

Fig. 4. XPS spectrum of $\mathrm{C} 1 \mathrm{~s}$ taken at $0^{\circ}$ (panel a) and $60^{\circ}$ (panel b) collection angle; the deconvolution of the peaks reveals the presence of the specific group of the polymer: $\mathrm{NC}=\mathrm{O}$ and $\mathrm{CNC}=\mathrm{O}$.

The nitrogen and oxygen content, evaluated from the intensity of the characteristic peaks, are, respectively, $17 \%$ and $16 \%$ of that of the carbon. In the surface sensitive configuration $\left(60^{\circ}\right.$ collection angle) the signal coming from N1s decreases to $14 \%$ of that of $\mathrm{C} 1 \mathrm{~s}$. Note that this decrease is close to the limit of the uncertainty of the XPS measurement (about 10\% of the ratios between concentrations of different elements), but could be compatible with the presence of some additional adventitious carbon (e.g. physisorbed $\mathrm{CO}_{2}$ ) at the surface. These results reveal a slightly higher carbon concentration with respect to oxygen and nitrogen, when compared to the expected atomic ratio for the copoly reported in Table 1 (19\% and $20 \%$, respectively), which may be due again to surface carbon contamination. This contamination arises mainly to the extended exposure of the sample to atmospheric environment before the measurements. A rough estimation of the amount of adventitious carbon can be obtained by comparing the measured and nominal $\mathrm{N} / \mathrm{C}$ and $\mathrm{O} / \mathrm{C}$ ratios of Table 1 : a value of contaminant of about $6 \%$ of the total elemental composition is estimated, consistent with data obtained on similar functionalization [24].

The deconvolution of the $\mathrm{C} 1 \mathrm{~s}$ peak shown in Fig. 4 allows disentangling the contributions from the different coordinations of $\mathrm{C}$ atoms in the polymer. The fitting has been performed with a Voigt line-shape for each component, with a fixed FWHM of $1.56 \mathrm{eV}$. This is consistent with the FWHM of the $\mathrm{C} 1 \mathrm{~s}$ peak from adventitious carbon, previously measured in the same experimental conditions on other samples [25].
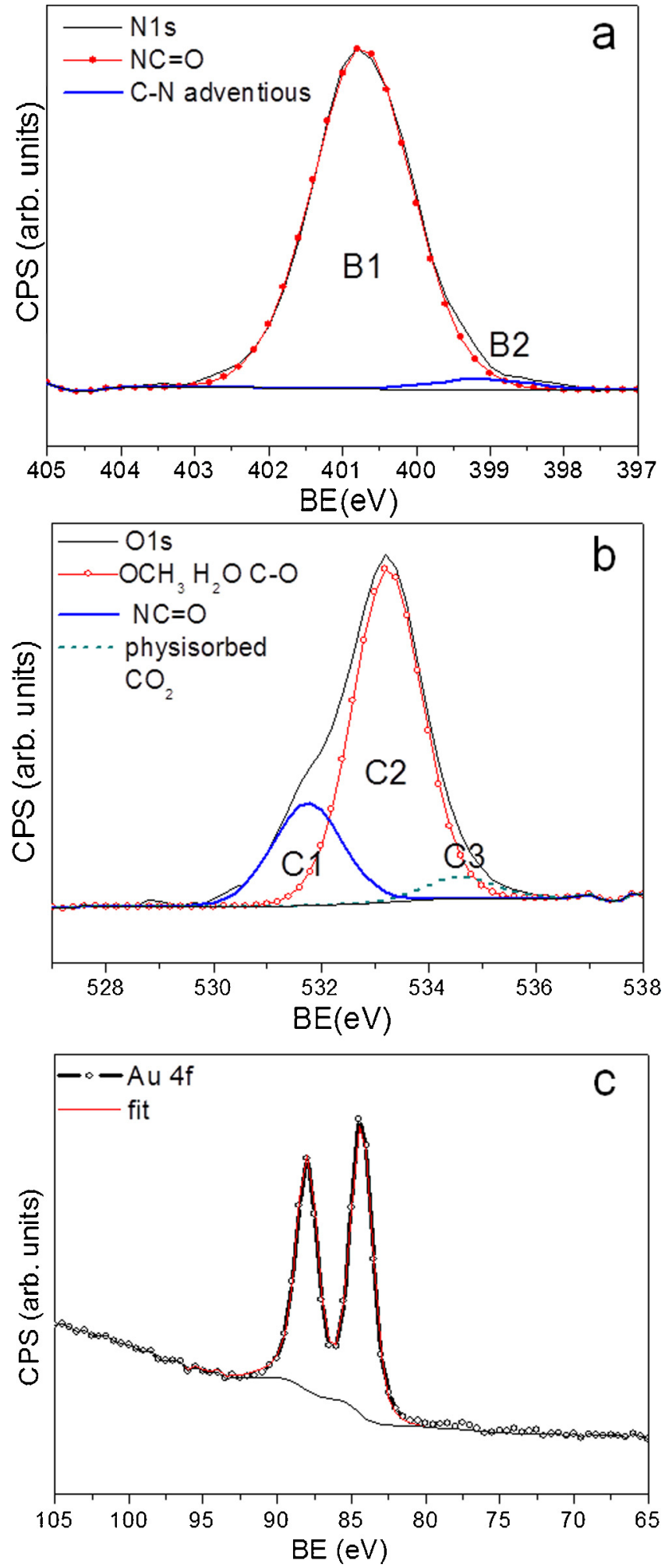

Fig. 5. XPS spectrum of N1s (panel a), $01 \mathrm{~s}$ (panel b) and Au $4 \mathrm{f}$ (panel c) at $60^{\circ}$ collection angle; while the first two spectra show the features coming from $-\mathrm{NC}=\mathrm{O}$ groups, the $\mathrm{Au} 4 \mathrm{f}$ peak lineshape presents the typical metallic character of a free gold.

Panel (a) $\left(0^{\circ}\right.$ collection angle $)$ and panel $(b)\left(60^{\circ}\right.$ collection angle $)$ of Fig. 4 show common features. The main peak $\left(A_{1}\right)$ is located at $285.6 \mathrm{eV}$ and represents about $63 \%$ of the entire $\mathrm{C} 1 \mathrm{~s}$ signal. As it can be ascribed both to adventitious carbon (carbon partially bounded to $\mathrm{O}$ and $\mathrm{N}[25]$ ) and $\mathrm{C}-\mathrm{C}$ bonds, it cannot be unambiguously 
Au
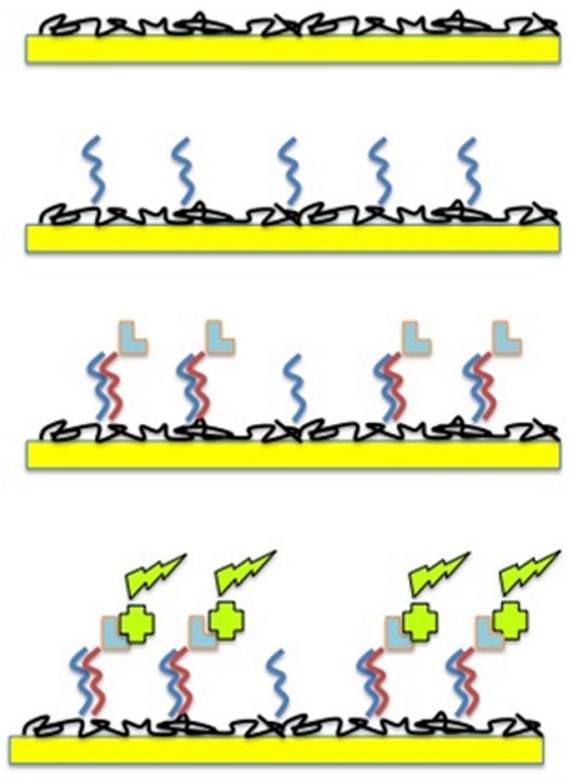

Preteatment by Oxygen plasma

Coating by copoly(DMA-NAS-MAPS)

Spotting of $\mathrm{NH}_{2}$-oligonucleotides

Capture of biotinilated
oligonucleotide

Production of chemiluminescence by the use of streptavidin labelled with HRP

Fig. 6. Scheme of the bioassay surface.

connected to the polymer coating. Two other contributions are visible in both panels of Fig. 4: $A_{2}(286.7 \mathrm{eV})$, which is due to the presence of $\mathrm{C}-\mathrm{O}$ and $\mathrm{C}-\mathrm{N}-\mathrm{C}=\mathrm{O}$ chemical bonds [26] and $A_{3}$ $(288.4 \mathrm{eV})$ coming from $\mathrm{CO}_{2}, \mathrm{NC}=\mathrm{O}$ and methoxy $\left(\mathrm{O}-\mathrm{CH}_{3}\right)$ groups. [26-28] The experimental weight of $A_{2}$ and $A_{3}$ are $22 \%$ and $15 \%$ of the whole $\mathrm{C} 1 \mathrm{~s}$ peak, respectively, but also in this case they can be only partially attributed to $C$ atoms within the polymer, due to some possible $\mathrm{CO}$ and $\mathrm{CO}_{2}$ contaminations contributing to $A_{2}$ and $A_{3}$. These values must be compared with the polymer chemical structure, from which the relative weight of the different carbon bonds can be evaluated. In a nominal polymer coating $\mathrm{C}-\mathrm{C}$ bonds (contributing to $A_{1}$ ) represent $50.5 \%$ of the entire carbon bonds, $\mathrm{C}-\mathrm{N}$ and $\mathrm{C}-\mathrm{O}$ bonds $\left(A_{2}\right) 31.5 \%$, while $\mathrm{NC}=\mathrm{O}, \mathrm{O}-\mathrm{C}=\mathrm{O}, \mathrm{O}-\mathrm{CH}_{3}$ groups (indicated as OMe in the polymer chemical structure of Fig. 1) $18.3 \%$.

The discrepancy between the expected ratios form the chemical formula and the experimental ones is consistent with the oxygen and nitrogen deficiency found in the composition analysis of Table 1 . Adventitious carbon contamination can clearly account for these results and prevents from a precise estimation of the coating composition via quantitative XPS analysis.

Finally note that, at $0^{\circ}$ collection angle (bottom panel of Fig. 4), an additional feature $\left(A_{4}\right)$ at $290 \mathrm{eV}$ is needed to fit the $\mathrm{C} 1 \mathrm{~s}$ peak. Due to the increased probing depth at normal emission, this feature can be attributed to some contaminants far away from the surface, most probably carbonates on the bare gold surface which can form during the coating in wet environment.

Spectra at $60^{\circ}$ collection angle of $\mathrm{N} 1 \mathrm{~s}$ and $\mathrm{O} 1 \mathrm{~s}$, are presented in Fig. 5. Also in this case the peaks have been decomposed using Voigt functions with fixed FWHM of $1.62 \mathrm{eV}$ and $1.53 \mathrm{eV}$, respectively, $[25,26]$.

The N1s spectrum presents two characteristic contributions: the main one at $400.7 \mathrm{eV}\left(B_{1}\right)$, corresponding to $\mathrm{C}-\mathrm{N}-\mathrm{C}$ and $\mathrm{N}-\mathrm{C}-\mathrm{O}$ bonds from the polymer [26] and a minor one at $399.1 \mathrm{eV}\left(B_{2}\right)$, corresponding to $\mathrm{C}-\mathrm{N}$ bounds from adventitious carbon [29]. $B_{2}$ is only $5 \%$ of the entire peak and can be attributed to contamination from adventitious carbon, as already seen from C1s spectra deconvolution. Regarding oxygen, three features give rise to the 01 s peak, but here the attribution is not straightforward. While the feature at $531.7 \mathrm{eV}\left(C_{1}\right)$ is due only to $\mathrm{NC}=\mathrm{O}$ groups [26], the prominent contribution at $533.3 \mathrm{eV}\left(C_{2}\right)$ can arise from the overlap of the signals from $\mathrm{H}_{2} \mathrm{O}(533.3 \mathrm{eV}), \mathrm{O}-\mathrm{CH}_{3}(533.2 \mathrm{eV})[28]$ and $\mathrm{C}-\mathrm{O}(533.6 \mathrm{eV})$ groups [30]. The minor feature at $534.9 \mathrm{eV}\left(C_{3}\right)$ might instead be due to physisorbed $\mathrm{CO}_{2}$. All these features in the $\mathrm{O} 1 \mathrm{~s}$ peak are consistent with the presence of the polymeric groups found from the deconvolution of N1s and C1s peaks, but a quantitative analysis here is prevented from the superposition of the characteristic signals.

In order to evaluate the impact of the polymer coating on the gold surface, we present in Fig. $5 \mathrm{c}$ the Au $4 \mathrm{f}$ peaks collected at $60^{\circ}$ in order to maximize the surface sensitivity. The continuous line represents a fit performed using the lineshape measured on the clean gold surface, before dip coating, in the same experimental conditions. The results seem to suggest that the gold surface is unchanged upon dip coating, without detectable traces of oxidization. However, previous studies have demonstrated that the Au surface can be oxidized by oxygen plasma treatments [31], therefore we can not exclude that, at least a small portion of the methoxysilane on the polymer might condensate with oxidized gold atoms strengthening the binding between the polymer and the surface which primarily is due to non covalent interactions such as van der Waals or hydrophobic forces.

In conclusion, both the AFM scratch test and the XPS analysis reveal that a continuous polymer is immobilized on the surface. In particular XPS shows the presence of the characteristic chemical groups from copoly(DMA-NAS-MAPS) on top of a gold surface preserving its chemical integrity upon coating.

\subsection{Hybridization experiments}

A hybridization test was carried out to prove that the functional polymer bind amino modified oligonucleotides with great efficiency and low background noise. A simple DNA hybridization experiment was performed to prove that the coating has introduced chemical reactive groups on the gold surface. A scheme 
Table 2

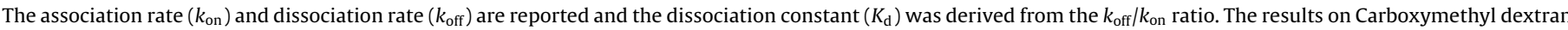
are representative of two independent experiments with similar results.

\begin{tabular}{|c|c|c|c|c|}
\hline \multirow[t]{2}{*}{ Functionalization } & \multicolumn{3}{|c|}{ FGF2/heparin interaction kinetic parameters: } & \multirow[t]{2}{*}{ References } \\
\hline & $k_{\text {on }}\left(\mathrm{s}^{-1} \mathrm{M}^{-1}\right)$ & $k_{\text {off }}\left(\mathrm{s}^{-1}\right)$ & $\overline{K_{d}(\mathrm{nM})}$ & \\
\hline Copoly(DMA-NAS-MAPS) & $8.22 \times 10^{4}$ & $1.54 \times 10^{-3}$ & 18.0 & Present work \\
\hline \multirow[t]{2}{*}{ Carboxymethyl dextran } & $9.0 \times 10^{3}$ & $3.8 \times 10^{-4}$ & 42.5 & [37] \\
\hline & $8.14 \times 10^{3}$ & $3.2 \times 10^{-4}$ & 38.0 & [38] \\
\hline
\end{tabular}

of a typical array experiment is shown in Fig. 6. Replicates of an oligonucleotide ligand are spotted on the polymer coated gold using a piezoelectric spotter. After washing and blocking the surface unreacted sites, the array is probed with a sample containing a complementary target oligonucleotide labeled with biotin. A detection step with streptavidin labeled with horse radish peroxidase (HRP) is then performed. The hybridization reaction was revealed by chemiluminescence using an enzyme, HRP, that catalyses the conversion of the enhanced chemiluminescent substrate into a sensitized reagent in the vicinity of the molecule of interest, which on further oxidation by hydrogen peroxide, produces a triplet (excited) carbonyl, which emits light when it decays to the singlet carbonyl. Enhanced chemiluminescence allows detection of minute quantities of a biomolecule. The strong signal to noise ratio of the oligonucleotide spots proves that the surface bind covalently amino-modified DNA molecules (Fig. 7). Chemiluminescence was chosen to prevent fluorescence quenching that would have occurred labeling the DNA with a fluorophore [32]. In this approach, luminol, one of the most widely used chemiluminescent reagents, is oxidized by peroxide and it results in creation of an excited state product called 3-aminophthalate. This product decays to a lower energy state by releasing photons of light. The distance from the surface is enough to prevent quenching.

Finally, to prove the practical exploitability of copoly(DMA-NASMAPS), a SPR assay was set up. Streptavidin was immobilized to a copoly(DMA-NAS-MAPS) -functionalized gold sensorchip and used to capture biotinylated heparin. Then, heparin immobilized to the gold surface was evaluated for its capacity to bind FGF2, one of the most important angiogenic growth factors largely studied for its heparin-binding capacity [33,34]. Injection of $100 \mathrm{ng} / \mathrm{mL}$ of heparin onto a copoly(DMA-NAS-MAPS)/streptavidin-functionalized sensorchip allows the immobilization of 233 resonance units (RU) equal to $17.1 \mathrm{fmol} / \mathrm{mm}^{2}$ of heparin. Relevant to note, in previous experiments, the injection of heparin onto streptavidin

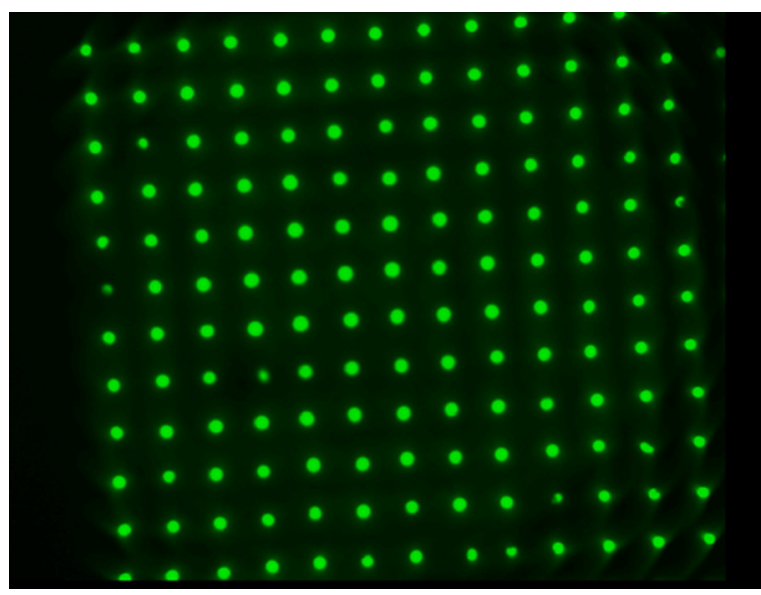

Fig. 7. Chemiluminescence signals of oligonucleotide spots after hybridization with complementary oligonucleotide labeled with biotin followed by incubation with streptavidin labeled with Horse Radish Peroxidase.

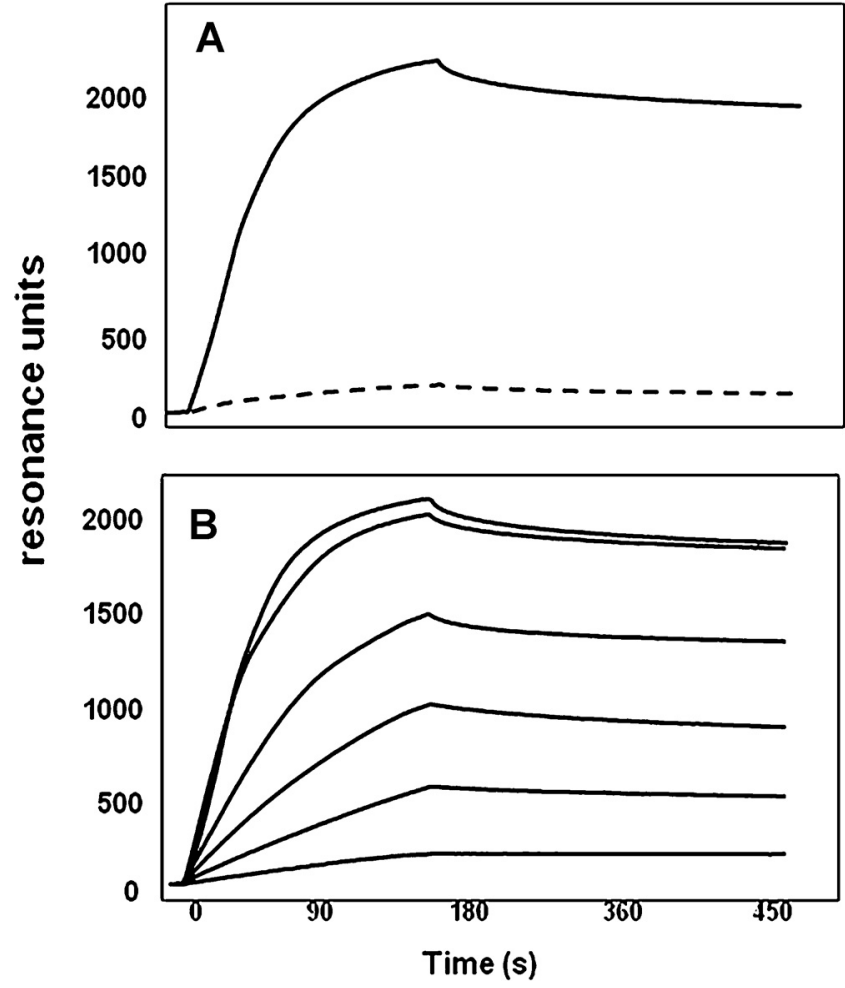

Fig. 8. SPR analysis of FGF2/heparin interaction. (A) Sensorgrams showing the binding of FGF2 (300 nM) to a copoly(DMA-NAS-MAPS)-functionalized gold layer coated with streptavidin alone (hatched line) or with streptavidin and biotinylated-heparin (straight line). (B) Blank-subtracted sensorgram overlay showing the binding of increasing concentrations of FGF2 $(300,150,75,36,18$ e $9 \mathrm{nM}$ from top to bottom) to a copoly(DMA-NAS-MAPS)-functionalized gold layer coated with streptavidin and biotinylated-heparin. In both the panels the response (in RU) was recorded as a function of biographies time.

immobilized to a carboxymethyl dextran-functionalized sensorchip lead to the immobilization of comparable amounts of heparin (from 5.8 to $9.5 \mathrm{fmol} / \mathrm{mm}^{2}$ ) $[35,36]$. We then studied the capacity of copoly(DMA-NAS-MAPS)/streptavidin-immobilized heparin to bind FGF2. As shown in Fig. 8A, when immobilized to a surface via copoly(DMA-NAS-MAPS)/streptavidin, heparin retains its capacity to bind FGF2 in a specific way, as demonstrated by the absence of interaction with immobilized streptavidin. Increasing concentrations of FGF2 were injected over the heparin surface to evaluate the kinetic parameters of FGF2/heparin interaction. As reported in Table 2 , very similar values of dissociation $\left(k_{\text {off }}\right)$ and association $\left(k_{\text {on }}\right)$ rates and of dissociation constant $\left(K_{d}\right)$ can be obtained from the analyses performed onto copoly(DMA-NAS-MAPS)- or carboxymethyl dextran-functionalized gold layers.

\section{Conclusions}

In this paper, a new method for functionalizing a gold surface with copoly(DMA-NAS-MAPS) is presented. The polymer is simply 
deposited by dip coating after an oxygen plasma treatment, followed by washing in water and drying under vacuum.

AFM scratch tests reveal the presence of a uniform polymeric coating with a thickness of $2.5 \mathrm{~nm}$. The XPS spectra from C1s $\mathrm{N} 1 \mathrm{~s}$ and $01 \mathrm{~s}$ levels present the typical fingerprints of the polymeric overlayer, i.e. the features arising from $\mathrm{NC}=\mathrm{O}$ and $\mathrm{OMe}$ groups. The chemical composition found by XPS reveals a slight deficiency of nitrogen and oxygen with respect to carbon. This can be due to a limited carbon contamination of the polymeric coming in wet and atmospheric environment. The analysis of the surface chemical properties of the gold substrate by XPS indicates no modifications induced by the coating process. The limited impact on the Au properties seen by XPS is confirmed also by functional tests performed on the polymer coated gold substrates.

Indeed, we showed the capability of the coating in the immobilization of biomolecules in different experiments. In particular, oligonucleotides were used as probes for the capture of complementary oligonucleotide strands detected by chemiluminescence. To assess the possibility to use copoly(DMA-NAS-MAPS) in SPR analysis, heparin was immobilized onto the polymer-coated gold surfaces of an SPR sensor and evaluated for its capacity to bind to FGF2, an important angiogenic factor. Three considerations can be drawn from the results of these experiments: (i) copoly(DMANAS-MAPS) allows the immobilization of heparin in amount that are comparable (if not higher) to those routinely immobilized onto different commercially available carboxymethyl dextran surfaces (i.e. CM5 and F1 sensorchips [37,38]); (ii) in our analyses, copoly(DMA-NAS-MAPS) turned out to be devoid of significant binding capacity, as shown by the very low level of aspecific binding of FGF2 to a copoly(DMA-NAS-MAPS) surface devoid of heparin (see Fig. 8A); (iii) the specific binding of FGF2 to copoly(DMA-NASMAPS)-immobilized heparin occurs with kinetic parameters that are comparable to those measured onto commercially available carboxymethyl dextran surfaces (Table 2 ). This is at variance with the higher simplicity and robustness of the process we introduced in this paper, which could find applications in many different biochemical procedures.

\section{Acknowledgements}

This work was partially supported by Fondazione Cariplo via the project SpinBioMed (Project No. 2008.2330). M. R and A. B. acknowledge Ministero dell'Istruzione, dell'Universita' e della Ricerca, Istituto Superiore di Sanita' (AIDS Project), and Fondazione CARIPLO (project No. 2008.2198) for financial support.

\section{References}

[1] J.D. Hoheisel, Microarray technology: beyond transcript profiling and genotype analysis, Nat. Rev. Gen. 7 (2006) 200-210.

[2] M.C. Pirrung, How to make a DNA chip, Angew. Chem. Int. Ed. 41 (2002) $1276-1289$

[3] R.L. Rich, D.G. Myszka, Higher-throughput, label-free, real-time molecular interaction analysis, Anal. Biochem. 361 (2007) 1-6.

[4] N.J. Ronkainen, H. Brian Halsall, W.R. Heineman, Electrochemical biosensors, Chem. Soc. Rev. 39 (2010) 1747-1763.

[5] V. Dugas, A. Elaissari, Y. Chevalier, Book section surface sensitization techniques and recognition receptors immobilization on biosensors and microarrays, in: M. Zourob (Ed.), Recognition Receptors in Biosensors, XIV, 1st ed., Springer, New York, 2010, pp. 47-134 (849 p.) http://dx.doi.org/10.1007/978-1-4419-0919-0_2

[6] M. Viganò, R. Suriano, M. Levi, S. Turri, M. Chiari, F. Damin, Glass silanization with blocked-isocyanate for fabrication of DNA microarrays, Surf. Sci. 601 (2007) 1365-1370.

[7] V.C. Martins, F.A. Cardoso, J. Germano, S. Cardoso, L. Sousa, M. Piedade, P.P. Freitas, L.P. Fonseca, Femtomolar limit of detection with a magnetoresistive biochip, Biosens. Bioelectron. 24 (2009) 2690.

[8] A. Ulman, Formation and structure of self-assembled monolayers, Chem. Rev. 96 (1996) 1533-1554.
[9] J.C. Love, L.A. Estroff, J.K. Kriebel, R.G. Nuzzo, G.M. Whitesides, Self-assembled monolayers of thiolates on metals as a form of nanotechnology, Chem. Rev. 105 (2005) 1103-1170.

[10] A.B. Steel, T.M. Herne, M.J. Tarlov, Electrochemical quantitation of DNA immobilized on gold, Anal. Chem. 70 (1998) 4670-4677.

[11] D. Shenoy, W. Fu, J. Li, C. Crasto, G. Jones, C. Di Marzio, S. Sridhar, M. Amiji, Surface functionalization of gold nanoparticles using hetero-bifunctional poly(ethylene glycol) spacer for intracellular tracking and delivery, Int. J. Nanomed. 1 (2006) 51-57.

[12] T.M. Herne, M.J. Tarlov, Characterization of DNA probes immobilized on gold surfaces, J. Am. Chem. Soc. 119 (1997) 8916-8920.

[13] C.-Y. Lee, H.E. Canavan, L.J. Gamble, D.G. Castner, Evidence of impurities in thiolated single-stranded DNA oligomers and their effect on DNA self-assembly on gold, Langmuir 21 (2005) 5134-5141.

[14] G. Pirri, F. Damin, M. Chiari, E. Bontempi, L.E. Depero, Characterization of a polymeric adsorbed coating for DNA microarray glass slide, Anal. Chem. 76 (2004) 1352-1358.

[15] M. Cretich, G. Di Carlo, R. Longhi, C. Gotti, N. Spinella, S. Coffa, C. Galati, L. Renna, M. Chiari, High sensitivity protein assays on microarray silicon slides, Anal. Chem. 81 (2009) 5197-5203.

[16] A. Isacchi, M. Statuto, R. Chiesa, L. Bergonzoni, M. Rusnati, P. Sarmientos, G. Ragnotti, M. Presta, A six-amino acid deletion in basic fibroblast growth factor dissociates its mitogenic activity from its plasminogen activator-inducing capacity, Proc. Natl. Acad. Sci. U.S.A. 88 (1991) 2628-2632.

[17] L. Sola, M. Chiari, Modulation of electroosmotic flow in capillary electrophoresis using functional polymer coatings, J. Chromatogr. A 1270 (2012) 324-329, http://dx.doi.org/10.1016/j.chroma.2012.10.039.

[18] P. Bergese, E. Bontempi, M. Chiari, P. Colombi, F. Damin, L.E. Depero, G. Oliviero G. Pirri, M. Zucca, Investigation of a biofunctional polymeric coating deposited onto silicon microcantilevers, Appl. Surf. Sci. 253 (2007) 4226-4231.

[19] R. Bertacco, M. Cantoni, M. Riva, A. Tagliaferri, F. Ciccacci, Epitaxial growth and characterization of layered magnetic nanostructures, Appl. Surf. Sci. 252 (2005) 1754.

[20] (a) A. Yalçin, F. Damin, E. Özkumur, G. di Carlo, B.B. Goldberg, M. Chiari, M.S. Ünlü, Direct observation of conformation of a polymeric coating with implications in microarray applications, Anal. Chem. 81 (2009) 625-630;

(b) R. Suriano, M. Levi, G. Pirri, F. Damin, M. Chiari, S. Turri, Surface behavior and molecular recognition in DNA microarrays from N,N-dimethylacrylamide terpolymers with activated esters as linking groups, Macromol. Biosci. 6 (2006) 719-729.

[21] A. Ohlander, C. Zilio, T. Hammerle, S. Zelenin, G. Klink, M. Chiari, K. Bock, A. Russom, Genotyping of single nucleotide polymorphisms by melting curve analysis using thin film semi-transparent heaters integrated in a lab-on-foil system, Lab Chip 13 (2013) 2075-2082.

[22] M. Cretich, V. Sedini, F. Damin, M. Pelliccia, L. Sola, M. Chiari, Coating of nitrocellulose for colorimetric DNA microarrays, Anal. Biochem. 397 (2010) 84-88.

[23] This normalization procedure would be rigorously correct for a film whose thickness is much larger than the electron escape depth, which is clearly not the case here. From the approximate formula $\lambda=0 . X^{1 / 2}$ valid for inorganic compounds [M. P. Seah and W. A. Dench, Quantitative electron spectroscopy of surfaces: a standard database for electron inelastic mean free paths in solids, Surf. Interface Anal. 1 (1979) 2] for C1s, N1s and 01s electrons we employed an escape depth of 31 Á, $30 \AA \hat{A}, 28 \AA$ Á, respectively, which corresponds to $\lambda=0.9$ $\mathrm{E}^{1 / 2}$.

[24] G. Di Carlo, F. Damin, L. Armelao, C. Maccato, S. Unlu, P.S. Spuhler, M. Chiari, Synthesis and conformational characterization of functional di-block copolymer brushes for microarray technology, Appl. Surf. Sci. 258 (2012) 3750-3756.

[25] D. Petti, M. Cantoni, M. Leone, R. Bertacco, E. Rizzi, Activation of ZrCo-rare earth getter films: an XPS study, Appl. Surf. Sci. 256 (2010) 6291-6296.

[26] I.F. Amaral, P.L. Ggranja, M.A. Barbosa, Chemical modification of chitosan by phosphorylation: an XPS, FT-IR and SEM study, J. Biomater. Sci. Polym. Ed. 16 (2005) 1575-1593.

[27] Ch. Ammon, A. Bayer, G. Held, B. Richter, Th. Schmidt, H.-P. Steinrück, Dissociation and oxidation of methanol on Cu(110), Surf. Sci. 507-510 (2002) $845-850$.

[28] Z. Zhang, Q. Fu, H. Zhang, Y. Li, Y. Yao, D. Tan, X. Bao, Enhanced methanol dissociation on nanostructured 2D Al overlayers, J. Phys. Chem. C 111 (2007) 13524-13530.

[29] B. Lindberg, R. Maripuu, K. Siegbahn, R. Larsson, C.G. Golander, J.C. Eriksson, ESCA studies of heparinized and related surfaces: 1. Model surfaces on steel substrates, J. Colloid. Interface Sci. 95 (1983) 308.

[30] Handbook of X-ray Photoelectron Spectroscopy, Parkin-Elmener Corp., Eden Praire Minnesota (USA), 1992.

[31] H. Ron, I. Rubinstein, Alkanethiol monolayers on preoxidized gold. Encapsulation of gold oxide under an organic monolayer, Langmuir 10 (1994) 4566-4573.

[32] G.P. Acuna, M. Bucher, I.H. Stein, C. Steinhauer, A. Kuzyk, P. Holzmeister, R. Schreiber, A. Moroz, F.D. Stefani, T. Liedl, F.C. Simmel, P. Tinnefeld, Distance dependence of single-fluorophore quenching by gold nanoparticles studies on DNA origami, ACS Nano 6 (2012) 3189-3195.

[33] B. Casu, M. Guerrini, A. Naggi, M. Perez, G. Torri, D. Ribatti, P. Carminati, G. Giannini, S. Penco, C. Pisano, et al., Short heparin sequences spaced by glycol-split 
uronate residues are antagonists of fibroblast growth factor 2 and angiogenesis inhibitors, Biochemistry 41 (2002) 10519-10528.

[34] B. Casu, M. Guerrini, S. Guglieri, A. Naggi, M. Perez, G. Torri, G. Cassinelli, D. Ribatti, P. Carminati, G. Giannini, et al., Undersulfated and glycol-split heparins endowed with antiangiogenic activity, J. Med. Chem. 47 (2004) 838-848.

[35] M. Donalisio, M. Rusnati, A. Civra, A. Bugatti, D. Allemand, G. Pirri, A. Giuliani, S. Landolfo, D. Lembo, Identification of a dendrimeric heparan sulfate-binding peptide that inhibits infectivity of genital types of human papillomaviruses, Antimicrob. Agents Chemother. 54 (2010) 4290-4299.

[36] A. Bugatti, P. Chiodelli, J. Rosenbluh, A. Loyter, M. Rusnati, BSA conjugates bearing multiple copies of the basic domain of HIV-1 Tat: prototype for the development of multitarget inhibitors of extracellular Tat, Antivir. Res. 87 (2010) 30-39.

[37] M. Presta, P. Oreste, G. Zoppetti, M. Belleri, E. Tanghetti, D. Leali, C. Urbinati, A. Bugatti, R. Ronca, S. Nicoli, E. Moroni, H. Stabile, M. Camozzi, G.A. Hernandez, S. Mitola, P. Dell'Era, M. Rusnati, D. Ribatti, Antiangiogenic activity of semisynthetic biotechnological heparins: low-molecular-weight-sulfated Escherichia coli K5 polysaccharide derivatives as fibroblast growth factor antagonists, Arterioscler. Thromb. Vasc. Biol. 25 (2005) 71-76.

[38] A. Bugatti, C. Giagulli, C. Urbinati, F. Caccuri, P. Chiodelli, P. Oreste, S. Fiorentini, A. Orro, L. Milanesi, P. D'Ursi, A. Caruso, M. Rusnati, Biochemical characterization of HIV-1 matrix protein p17 interaction with heparin, J. Biol. Chem. 288 (2013) 1150-1161.

\section{Biographies}

Daniela Petti received B.S. and M.S. degrees in Physics Engineering from Politecnico di Milano in 2004 and 2006. In 2010 she obtained her PhD in Physics from Politecnico di Milano, where she is actually Assistant Professor in the Physics Department. She is co-author of more than 25 research papers and 2 patents. She started her activity in the field of spintronics. Currently, the main research activity is related to the applications of nanomagnetism to biology and medicine. Her interests include the development of magnetic platforms for biosensing and for on chip fine manipulation of functionalized magnetic nanoparticles for in-vitro applications.

Andrea Torti received B.S., M.S. degrees in Physics Engineering and $\mathrm{PhD}$ in Physics from Politecnico di Milano in 2006, 2009 and 2013, respectively. At the beginning of 2013 he joined the Electronic Department of Politecnico di Milano to work on the integration of biosensors and CMOS technology. Actually, he is Technical Device Engineer at ST Microelectronics, Agrate Brianza (Italy). He started his activity in the field of Nanomagnetism and Nanomedicine. Currently his research interests are in the smart power integrated devices field.

Francesco Damin was born in 1971 in Busto Arsizio (VA, Italy), graduated in Biological Science, specialty Molecular Biology, at Università degli Studi di Milano in 1998. He was recipient of several fellowships and research contracts from ICRM, C.N.R. where he was appointed Research Scientist in 2011. His research interests, documented by more than 35 publications on peer-reviewed journals and several communications at congresses, deal with the development of surfaces to the analyses of DNA and proteins with the microarray technology.

Laura Sola earned her M.S. Degree in Chemistry and Pharmaceutical Technologies and her Ph.D. in Drug Chemistry at University of Milan in 2008 and 2012, respectively. She currently holds a post-doctoral appointment at the Institute of
Chemistry for Molecular Recognition, CNR where she develops novel polymeric coatings for immobilizing biomolecules and techniques for molecular recognition on supports made of various materials. These are used in biomedical applications of biosensors and Lab on Chip analysis. Laura specializes in chemical synthesis of monomers, polymers and linear matrices for DNA, DNA sequencing by capillary electrophoresis and novel capillary polymer coatings enabling improved analysis.

Marco Rusnati gained his degree at the Institute of Biochemistry, University of Milan, Italy, in 1985. He is now associated professor, Section of Experimental Oncology and Immunology, University of Brescia. His researches focused on: 1983-85: purification and biochemical characterization of D-amino acid oxidase. 1986-1992: purification of angiogenic factors, identification of their functional domains. 1992-present: interaction of angiogenic factors with receptors and extracellular binders. 1996-present: biological activity of HIV-1 Tat, study of its interaction with receptors and extracellular binders. 2001-present: study of interactions of viral proteins by surface plasmon resonance. He is author of 110 scientific publications in peer-reviewed journals.

Edoardo Albisetti obtained B.S. and M.S. degrees in Physics Engineering from Politecnico di Milano in 2008 and 2010. Currently, he is a PhD student in the Physics Department of Politecnico di Milano. His research activity mainly concerns the development of spintronic devices and their application in biology. In this framework, he developed a sensing platform based on magnetoresistive sensors for detection of molecular recognition events and a system based on magnetic domain wall conduits for providing local mixing of solutions in microfluidic systems. Magnetic domain wall conduits are also used for ultra-fine spatial manipulation of magnetic nanoparticles for in-vitro applications.

Antonella Bugatti obtained her B.S. degree in Biomedical Laboratory Technician from University of Verona. Since 2006 she is Research fellow at the Unit of Experimental Oncology and Immunology, University of Brescia. She is co-author of 25 scientific publications in peer-reviewed journals. Her expertise is related to cell and molecular biology assays, protein-protein interaction (SPR technology), in-vitro assays (endothelial cell proliferation, migration, invasion and morphogenesis). Her research interests are associated to the study of protein-protein interaction by surface plasmon resonance.

Riccardo Bertacco got his degree in Electronic Engineering at Politecnico di Milano in 1994. He obtained a permanent position at the Physics Department of Politecnico di Milano in 1999 and the PhD in Physics in 2000. Actually, he is Associate Professo at the Physics Department of Politecnico di Milano, where he leads the NanoBiotechnology and Spintronics group of the LNESS center. He is the technical responsible for the realization of a new clean-room for micro and nanofabrication at Politecnico di Milano. He is author of about 100 papers in international journals, a chapter of a book and 6 patent applications.

Marcella Chiari graduated in Chemistry and Pharmaceutical Techniques at the Istituto di Chimica Organica, Facoltà di Medicina, Università di Milano in 1982. She received the Diploma in Clinical Biochemistry, Università di Milano in 1990. Since 1992 she has been Senior Researcher at the ICRM, CNR, where she leads the laboratory "Development of Analytical Microsystems: Her research activity is documented by more than 100 publications and several patents. She has been a contractor of the EC in the framework of different projects and responsible for several national research programs. 